\title{
Solving the problem of aircraft safety during combat shooting by air defense means
}

\author{
Marat Meyerbekov $^{1}$, Kuandyk Zakariya ${ }^{2}$, Karassay Kurmanseitov $^{3}$, Adilbek Bekmagambetov ${ }^{4}$ \\ ${ }^{1}$ National University of Defense of the First President of the Republic of Kazakhstan - Elbasy, Nur-Sultan, \\ Kazakhstan, maratmeyerbekov@bk.ru \\ ${ }^{2}$ National University of Defense of the First President of the Republic of Kazakhstan - Elbasy, Nur-Sultan, \\ Kazakhstan, kuandyk.zakariya@inbox.ru \\ ${ }^{3}$ National University of Defense of the First President of the Republic of Kazakhstan - Elbasy, Nur-Sultan, \\ Kazakhstan, karassay.kurmanseitov@mail.ru \\ ${ }^{4}$ National University of Defense of the First President of the Republic of Kazakhstan - Elbasy, Nur-Sultan, \\ Kazakhstan, adilbek.bekmagambetov@mail.ru
}

\begin{abstract}
The article raises the issue of aircraft safety during practical shooting by air defense calculations at targets. In order to ensure safety, information about the flight path of the target missile is required. To solve the problem of determining the trajectory data of the target rocket flight, it is proposed to use the radio-detonator of an anti-aircraft guided missile, converted into a missile target, in a new capacity - a source of radar information. This radar information is received by two receiving points located on the ground and separated from each other. Information from two receiving stations calculates the current projected range of the missile target using the triangulation method. The calculated projection range of the missile target is compared with the allowed range.if the flight of the missile target goes beyond the boundaries of the permitted sector, the "self-destruct"command is issued on Board the missile target. The principle of operation of the radio detonator allows for minimal changes in the design to use it in solving problems of aircraft safety during combat firing by air defense combat calculations. The use of a converted radio detonator, two receiving stations separated from each other and the calculation of the projection range by triangulation will ensure the safety of aircraft and people and objects on the ground is confirmed by the proposed technical solution and mathematical formulas.
\end{abstract}

Key words : security, radar, anti- aircraft guided missile, target missile, radio detonator.

\section{INTRODUCTION}

Ensuring the safety of aircraft that perform regular flights during exercises with live fire by air defense means is an urgent problem. This is proved by the tragedy of 2001, when a Tu-154 of the Sibir airlines crashed over the Black sea. It was on a flight from tel Aviv to Novosibirsk, with 66 passengers and 12 crew members on Board, all of whom were killed. The interstate aviation Committee concluded that the plane was shot down by an anti-aircraft guided missile launched from the S-200 complex, while Ukraine was conducting air defense exercises [1].

Purpose of research. Development of technical solutions for determining the trajectory data of the flight of a missile target, using the radio detonator of an anti-aircraft guided missile, converted into a missile target, in a new capacity as a source of radar information.

\section{MATERIALS AND METHODS}

The research material is a radio-detonator of an anti-aircraft guided missile and the development of a technical solution for its use in a missile target in another capacity. To achieve the research goal, statistical methods, system analysis and modeling were used.

\section{RESULTS AND DISCUSSION:}

In Soviet times, live-fire exercises of the air defense forces were conducted at ranges that had large areas that allowed for safe firing by air defense means. In addition, they were equipped with special telemetry equipment that allowed them to track the flight paths of targets and anti-aircraft guided missiles. Currently, there is no such equipment at the Saryshagan test site (Kazakhstan), and time requires the creation of technical means that can solve the problem of determining the trajectory data of the target rocket flight, in order to ensure the safety of ground objects, as well as to confirm the target's defeat, calculations of the air defense forces.

Air defense systems have anti-aircraft missile systems (SAMS) and systems that determine the current coordinates (sight) of the target and the missile, develop control commands for the missiles to guide them to the target. Target and missile sightings are based on the following principles: 
target-active radar with passive response; missile-active radar with active response (missile responder) [2].

Ground control station Sam irradiates the target. Simultaneously with the signals reflected from the target, the signals of the missile responder are received. Simultaneous reception of signals reflected from the target and the missile signals allows you to determine the position of the missile relative to the target at any time. Data on the position of the missile and the target are received by the ground station's counting and decision device, which generates control commands transmitted to the missile. The principle of operation of the pulse radio control and sighting is based on determining the position of the missile relative to the target at any time, followed by the development of a command to control the missile.

When using an anti-aircraft missile as a missile target, determining its coordinates according to the responder's data to control the performance of the missile target of the specified flight path is not advisable for reasons:

- the ground control station of the target rocket issues control commands directly to the target rocket to work out the specified flight path, i.e. perform performing tasks. System that performs performing the task, can not effectively carry out the tasks of control. Therefore, separate ground control stations are needed in the system of measuring means of the polygon, especially if this is related to the safety of the target rocket application;

- structurally, the Respondent's antennas are located in the tail section at the end of the target rocket, which will definitely make it difficult to use information from the Respondent to obtain trajectory data of the target flight at control ground stations, since ground control stations are located in other areas of the terrain;

- re-equipment of the missile to receive information from the responder (transfer of the responder's antennas to the front of the rocket) or modification of the ground control station, in order to obtain reliable information about the flight of the target, for control ground stations, will lead to significant material costs.

To solve the problem of determining the trajectory data of the flight of a missile target, it is proposed to use the radio detonator of an anti-aircraft guided missile, converted into a missile target, in a new capacity as a source of radar information.

Radio controlled fuses included in the on-Board equipment surface to air missile and is designed to generate pulse triggering (initiation) at undermining the warhead anti-aircraft missiles when approaching a target at a time when the greatest defeat the purpose of the elements of combat units $[3,4$,$] .$

The radio fuse consists of an antenna system, a transmitter with a power supply, and a receiver. The antenna system is designed for radiating radio pulses in the direction of the target and receiving signals reflected from it [3, Fig. 1]. the directional Diagram of the antenna system of the radio fuse for transmission and reception has the form of a funnel with a changing angle depending on the duration of the command
"K4" at the vertex $\varphi$. the Command "K4" is issued from the ground control point on Board the rocket in flight. The duration of the command depends on the relative speed of the missile's approach to the target [3, p.12-28]. The total radiation pattern of the radio fuse antenna system is shown in figure 1 .

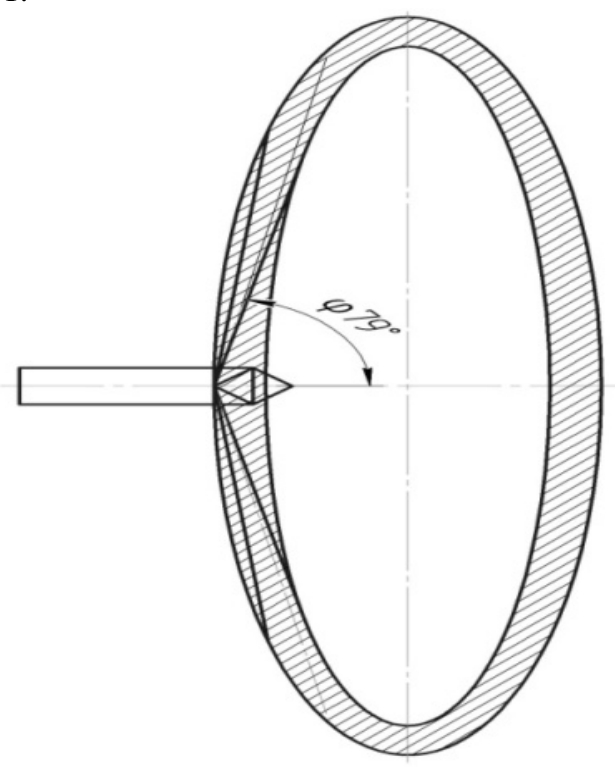

Figure 1: Total radiation pattern of the antenna system

The transmitter is designed to generate high-frequency pulses emitted by the transmitting antenna into space. It begins to work on the command "K3" (the command of cocking the radio fuse), which is issued from the ground control point on Board the rocket in flight [3, p. 11-35].

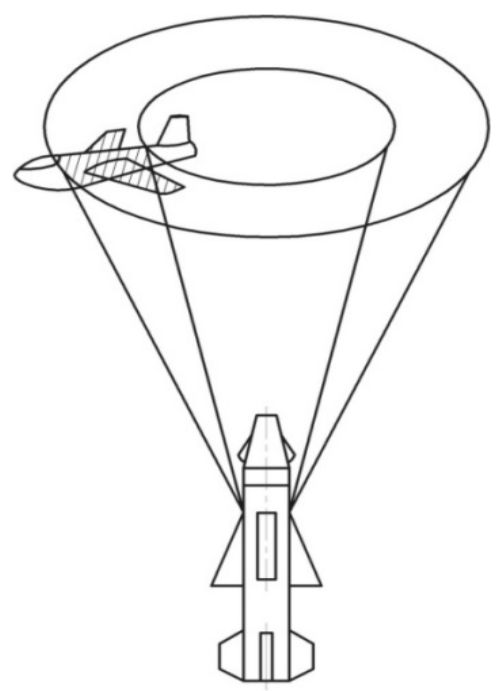

Figure 2: The case of a missile meeting with a target The receiver receives and amplifies the signal reflected from the target, generates a trigger pulse and outputs it to the safety-actuating mechanism [4, Fig. 1]. The safety-actuating mechanism ensures the safety of the explosive device during operation, start and on the trajectory until the end of cocking and serves to issue a detonation pulse to the initiating charge 
of the warhead [3, p.70]. One of the possible cases of a missile meeting with a target is shown in figure 2.

The principle of operation of the pulse radio fuse is based on the use of the pulse method of active radar [3, p.7-12]. When the command "K3" is received, from the ground control point on Board the rocket in flight, the transmitter of the radio fuse is turned on. Through the transmitting antenna, energy is radiated to the surrounding space in the form of short high-frequency pulses. In case of contact with targets in the radiation pattern of the antenna system to the input of the receiver receives reflected from the target signals. The signals reflected from the target are processed in the receiver and generate a trigger signal, i.e. issues an impulse to detonate the warhead of the missile through the safety-actuating mechanism, to hit the target.

When converting an anti-aircraft missile into a missile target, the radio fuse is not used for its intended purpose, so it is advisable to use the radio fuse as a source of radar information. Figure 3 shows the solution to the problem of ensuring the safety of ground objects from a target rocket in flight, when using a radio fuse as a source of radar information to determine the trajectory data of the target rocket flight.

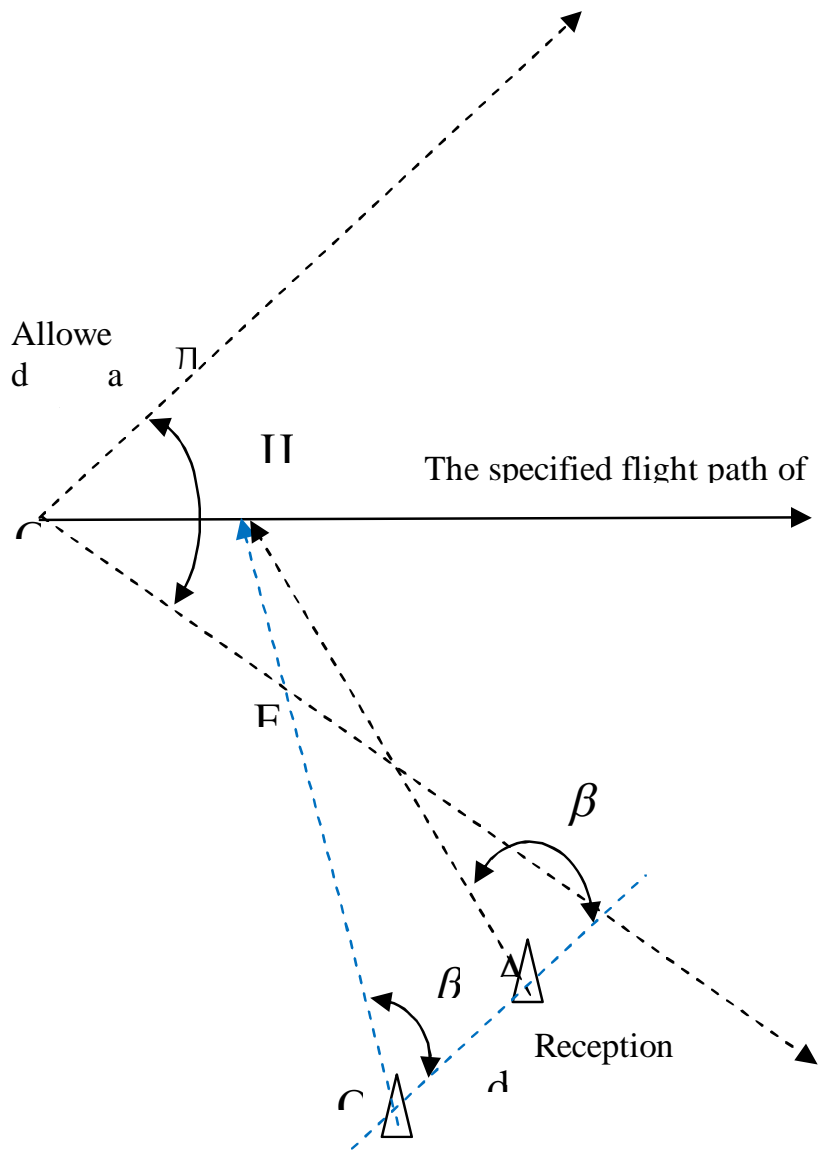

The main reception

Figure 3: Ensuring the safety of ground objects from a missile target in flight, when using radio explosives as a source of radar information
The target is launched from the launch point of target C. the target is Flown in the permitted flight sector. In flight, the bearing of the target is determined by two receiving stations, the main one at point $\mathrm{O}$, and the additional one at point $\mathrm{A}$. The distance to the target is calculated by solving the triangulation problem based on certain directions. The triangulation problem is solved by a logical device based on the main receiving center. In this case, the source of radar information is proposed to use the generated pulses of high-frequency energy of the radio fuse.

Figure 4 shows the determination of the range by the angle-measuring method[5].

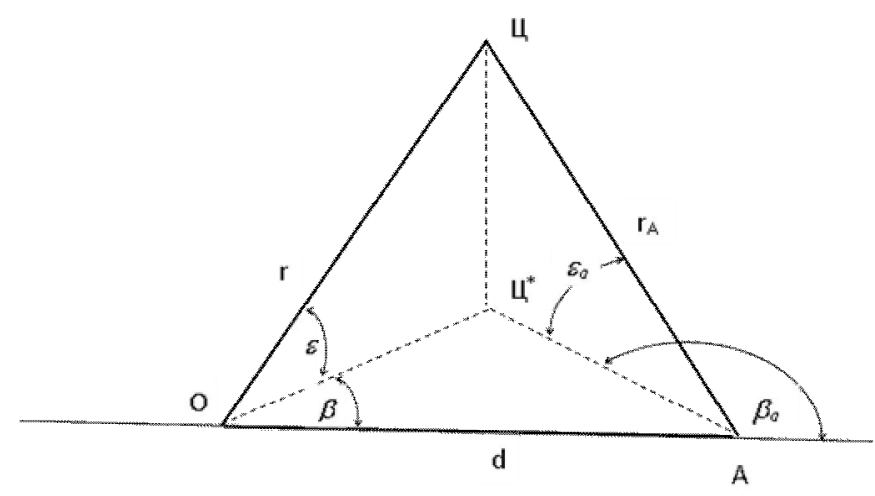

Figure 3: Determination of the range by the angle-measuring method

One receiving point is located at point $\mathrm{O}$, and the second at point $A$. It is sufficient to measure three angular coordinates: azimuth $\beta, \beta_{\mathrm{a}}$ and elevation $\varepsilon\left(\varepsilon_{\mathrm{A}}\right)$ or the elevation angles $\varepsilon, \varepsilon_{\mathrm{a}}$ and azimuth $\beta\left(\beta_{\mathrm{a}}\right)$.The expression connecting the target range with $\beta, \beta_{\mathrm{a}}, \varepsilon$ has the form [4, p. 146-147]:

$r=d * \sin \beta \alpha /(\cos \approx \sin (\beta \alpha-\beta))(2)$

Given that the distance from the air object to the receiving centers is sufficient projection, i.e. $\varepsilon=0(\cos 0=1)$. The formula will take the following form:

$r=d * \sin \beta a /(\sin (\beta a-\beta))(3)$

The logic device calculates the current projected range to the missile target $\left(\mathrm{O} \mathrm{OC} \rrbracket{ }^{\wedge *}\right)$ using formula 2 . The calculated current ranges are compared with the ranges to the boundaries of the permitted flight sector of the missile target (OE and OD).

If: |『 OC \ $\wedge^{*}|<| \mathrm{OE} \mid$ or $\left|\llbracket \mathrm{OC} \rrbracket{ }^{\wedge} *\right|>|\mathrm{OD}|$, then a self-destruct command is issued on Board the missile target. This ensures the flight of the missile target, only in the permitted flight sector.

In addition, a change in the target's flight course, when an anti-aircraft guided missile is detonated in the area of the missile target, will be a confirmation of the defeat of the missile target by the calculations of the air defense forces.

Changing the flight of a missile target on the course is determined by the above method - calculating the range to the missile target by solving a triangulation problem.

The change in the flight of a missile target by height can not be determined by the above method, because the range from 
Marat Meyerbekov et al., International Journal of Emerging Trends in Engineering Research, 8(10), October 2020, 7554 - 7559

the air object to the receiving centers is used projection, which is a disadvantage.

Basic signs of defeat of target missile anti-aircraft guided missile:

- simultaneous disappearance of pulses of high frequency energy attack missile target after the detonation of the warhead anti-aircraft guided missile, in both reception centres.

- change in the flight of the missile target on the course after the detonation of the anti-aircraft guided missile warhead, at both receiving centers.

When working in normal mode, the radio fuse is an active radar station with a passive response from the target. The maximum range of active radar for passive targets is determined by the basic radar equation[6]:

$A_{\max }=\sqrt[4]{\frac{F_{h} G_{n} G_{n} \sigma_{u} \lambda^{2}}{(4 \pi)^{3} p_{\min }}}(4)$

where: $P \_i$-radiated energy of the transmitter;

G_i,G_p-gain coefficients of the transmitting and receiving RF antennas;

$\sigma_{-}$c-effective reflecting surface of the target;

$\lambda$-wavelength;

$\mathrm{P}_{-}$(p. min) - the minimum sensitivity of the receiver

When the radio fuse is used for a new purpose, it will be a radar station with active radiation. Ground receiving stations, tuned to the frequency of the probing pulse of the radio transmitter, will receive signals from the maximum range, which is determined by the equation [7]:

$I_{\max }=\sqrt{\frac{P_{u} G_{u} G_{n} A^{2}}{(4 \pi)^{2} F_{\mathrm{m}}}}(5)$

Comparison of equations (4) and (5) shows that the actions of systems with active radiation under equal conditions are significantly longer than the range of active radar for passive targets.

When using the radio fuse for a new purpose (radar station with active radiation), under equal conditions, the receiving stations will receive signals from the radio fuse with a longer range than the standard application (active radar station with a passive response from the target).

If the detection range of the receiving stations of the sounding signals of the radio fuse needs to be increased, this will be possible by improving the directional coefficient of the receiving antenna and the sensitivity of the receiving device of ground control stations.

\section{CONCLUSION}

The solution of the technical problem of determining the trajectory data of the flight of a missile target is implemented by the method of triangulation, in order to ensure the safety of people and objects during combat firing by air defense means.

\section{ACKNOWLEDGEMENT}

The authors are very grateful to the Ministry of education and Science of the Republic of Kazakhstan for providing financial assistance in conducting this research.

\section{REFERENCES}

(Periodical style)

1. Ahmad, Z., and B.J. Abdul Aleem (2009). Erosion-Corrosion Behavior of PlasmaSprayed Nanostructured Titanium Dioxide Coating in Sodium Chloride-Polystyrene Slurry. Corrosion, 65, 9, 611 - 623.

2. Bhadra, S., Singha, N. K., Lee, J. H., and D. Khastgir (2009). Progress in preparation, processing and applications of polyaniline. Prog. Polym. Sci., 34, 783-810.

3. Bhadra, S., Singha, N. K., and D. Khastgir (2011). Polyaniline based anticorrosive and anti-molding coating. Journal of Chemical Engineering and Materials Science, 2(1), 1-11.

4. Bibber, J. W. (2009). Chromium-free conversion coatings for zinc and its alloys. Journal of Applied Surface Finishing, 2 (4), 273-275.

5. Bousser E., Benkahoul M., Martinu L., and Klemberg-Sapieha J.E. (2008). Effect of Mi $\square$ crostructure on the erosion resistance of $\mathrm{Cr}-\mathrm{Si}-\mathrm{N}$ coatings. Surface \& Coatings Technology, 203, $776-780$.

6. Belotserkovsky M., Nurakov S. (2019). Methods of coating deposition in mechanical engineering: Textbook. Almaty: SSK, 176.

7. Creus, J., Brezault, F., Rebere, C., and M. Gadouleau (2006). Synthesis and characteri $\square$ sation of thin cerium oxide coatings elaborated by cathodic electrolytic deposition on steel substrate, Surf. Coat. Technol. 200, 14-15.

8. Deen, K. M., Ahmad, R., and I.H. Khan (2009). Corrosion Protection Evaluation of Mild Steel Painted Surface by Electrochemical Impedance Spectroscopy. Journal of Quality and Technology Management, 5, 1, 6 .

9. Durodola, B. M., Olugbuyiro, J. A. O., Moshood, S. A., Fayomi, O. S. and A.P.I. Po $\square$ poola (2011). Study of Influence of Zinc Plated Mild Steel Deterioration in Seawater Environment. Int. J. Electrochem. Sci., 6, 5605 - 5616.

10. Davydov V. M., Zuev V. V., Ponochevny P. N. (2013). Analysis of international practice of profile and three-dimensional surface roughness assessment. Electronic scientific publication Scientific notes of the Pacific state University, 4 (4), 1061-1074.

11. Fayomi O. S. I. and A.P.I Popoola (2012). An Investigation of the Properties of Zn Coated Mild Steel, Int. J. Electrochem. Sci., 7, $6555-6570$.

12. Gasem, Z.M. (2013). ME 472: Corrosion engineering 1, ocw.kfupm.edu.sa/ocw.cours $\square$

es/users062/ME4720102/LectureNotes/impact

of

Corrosion.pdf, accessed on 26/01/2013.

13. Guosheng, H. Gu Daming, g., Li Xiangbo, L., and X. Lukuo (2013). Corrosion Behavior of Oxyacetylene Flame Sprayed Zn-Ni Composites Coating with Spray-dried 
Agglomerating Powders in Natural Seawater, Int. J. Electrochem. Sci., $82905-2917$.

14. Hammer, P., F. C. dos Santos, B. M. Cerrutti, S. H. Pulcinelli and C. V. Santilli (2012). Corrosion Resistant Coatings Based on Organic-Inorganic Hybrids Reinforced 264 Developments in Corrosion Protection by Carbon Nanotubes, Recent Researches in Corrosion Evaluation and Protection, Prof. Reza Shoja Razavi (Ed.), ISBN: 978-953-307-920-2.

15. Hara, M., Ichino, R., Okido, M., and N. Wadab (2003). AlN formation and enhance $\square$ ment of high-temperature oxidation resistance by plasma-based ion implantation, Surf. Coat. Technol. 169-170, 359-362.

16. Breunl T. Embedded robotic systems: design and application of mobile robots with embedded control systems. - Moscow: IKI, 2012. -520 p.

17. H. Nyquist. Certain topics in telegraph transmission theory. Trans. AIEE, vol. 47, pp. 617—644, Apr. 1928.

18. Zhantlesov Zh. Kh., Gruzin V. V., Zhantlesov.E. Zh. "Method of object scanning" patent of the Republic of Kazakhstan No. 32026 dated 31.03.2017.

19. Watts, A.C.; Ambrosia, V.G.; Hinkley, E.A. Unmanned aircraft systems in remote sensing and scientific research: Classification and considerations of use. Remote Sens. 2012, 4, 1671-1692.

20. Dalamagkidis, K. "UAV Applications" in Handbook of Unmanned Aerial Vehicles; Springer: Berlin/Heidelberg, Germany, 2015; pp. 2639-2860.

21. Salamí, E.; Barrado, C.; Pastor, E. UAV flight experiments applied to the remote sensing of vegetated areas. Remote Sens. 2014, 6, 11051-11081.

22. Whitehead, K.; Hugenholtz, C.H. Remote sensing of the environment with small unmanned aircraft systems (UASs), part 1: A review of progress and challenges. J. Unmanned Veh. Syst. 2014, 2, 69-85.

23. Gonzalez, L.F.; Montes, G.A.; Puig, E.; Johnson, S.; Mengersen, K.; Gaston, K.J. Unmanned aerial vehicles (UAVs) and artificial intelligence revolutionizing wildlife monitoring and conservation. Sensors 2016, 16, 97.

24. Achille, C.; Adami, A.; Chiarini, S.; Cremonesi, S.; Fassi, F.; Fregonese, L.; Taffurelli, L. UAV-based photogrammetry and integrated technologies for architectural applications-Methodological strategies for the after-quake survey of vertical structures in Mantua (Italy). Sensors 2015, 15, 15520-15539.

25. Bhardwaj, A.; Sam, L.; Bhardwaj, A.; Martín-Torres, F.J. LiDAR remote sensing of the cryosphere: Present applications and future prospects. Remote Sens. Environ. 2016, 177, 125-143.
26. Royo, P.; Pastor, E.; Barrado, C.; Cuadrado, R.; Barrao, F.; Garcia, A. Hardware Design of a Small UAS Helicopter for Remote Sensing Operations. Drones 2017, 1, 3.

27. Royo, P.; Barrado, C.; Cuadrado, R.; Pastor, E.; Barrao, F.; Garcia, A. Development of a small UAS helicopter for remote sensing operations. In Proceedings of the 2016 IEEE/AIAA 35th Digital Avionics Systems Conference (DASC), Sacramento, CA, USA, 25-29 September 2016; pp. 1-25.

28. MacFarlane, J.W.; Payton, O.D.; Keatley, A.C.; Scott, G.P.; Pullin, H.; Crane, R.A.; Smilion, M.; Popescu, I.; Curlea, V.; Scott, T.B. Lightweight aerial vehicles for monitoring, assessment and mapping of radiation anomalies. J. Environ. Radioact. 2014, 136, 127-130.

29. Martin, P.G.; Payton, O.D.; Fardoulis, J.S.; Richards, D.A.; Scott, T.B. The use of unmanned aerial systems for the mapping of legacy uranium mines. J. Environ. Radioact. 2015, 143, 135-140.

30. Martin, P.G.; Payton, O.D.; Fardoulis, J.S.; Richards, D.A.; Yamashiki, Y.; Scott, T.B. Low altitude unmanned aerial vehicle for characterising remediation effectiveness following the FDNPP accident. J. Environ. Radioact. 2016, 151, 58-63.

31. Martin, P.G.; Kwong, S.; Smith, N.T.; Yamashiki, Y.; Payton, O.D.; Russell-Pavier, F.S.; Fardoulis, J.S.; Richards, D.A.; Scott, T.B. 3D unmanned aerial vehicle radiation mapping for assessing contaminant distribution and mobility. Int. J. Appl. Earth Obs. Geoinf. 2016, 52, 12-19.

32. Martin, P.G.; Moore, J.; Fardoulis, J.S.; Payton, O.D.; Scott, T.B. Radiological assessment on interest areas on the sellafield nuclear site via unmanned aerial vehicle. Remote Sens. 2016, 8, 913.

33. Aleotti, J.; Micconi, G.; Caselli, S.; Benassi, G.; Zambelli, N.; Calestani, D.; Zanichelli, M.; Bettelli, M.; Zappettini, A. Unmanned aerial vehicle equipped with spectroscopic CdZnTe detector for detection and identification of radiological and nuclear material. In Proceedings of the 2015 IEEE Nuclear Science Symposium and Medical Imaging Conference (NSS/MIC), San Diego, CA, USA, 31 October-7 November 2015; pp. 1-5.

34. Cai, C.; Carter, B.; Srivastava, M.; Tsung, J.; Vahedi-Faridi, J.;Wiley, C. Designing a radiation sensing UAV system. In Proceedings of the 2016 IEEE Systems and Information Engineering Design Symposium (SIEDS), Charlottesville, VA, USA, 29-29 April 2016; pp. 165-169. 
35. Behnke, D.; Rohde, S.;Wietfeld, C. Design and experimental validation of UAV-assisted radiological and nuclear sensing. In Proceedings of the 2016 IEEE Symposium on Technologies for Homeland Security (HST), Waltham, MA, USA, 10-11 May 2016; pp. 1-6.

36. Sydyknazarov, M.-A., Karzhaubay, J., Sydyknazarova, S., Bayurzhan, M. Values of the youth of Kazakhstan. New Educational Review, 2018, 52(2), c. 137-148.

37. Li, B.; Zhu, Y.;Wang, Z.; Li, C.; Peng, Z.R.; Ge, L. Use of multi-rotor unmanned aerial vehicles for radioactive source search. Remote Sens. 2018, 10, 728.

38. Aubakirova, G., Adilbekov, Z., Narbayev, S. Influence of water mineralization on zooplankton productivity in reservoirs of Akmola region. Periodico Tche Quimica, 2020, 17(34), c. 520-527

39. Aubakirova, G.A., Pishenko, Y.V., Maikanov, B.S. Comprehensive study of the Ashykol and Kumkol lakes of Akmola Oblast of the North Kazakhstan. Mediterranean Journal of Social Sciences, 2014, 5(23), c. 2607-2611

40. Aubakirova, G.A., Syzdykov, K.N., Kurzhykayev, Z., Sabdinova, D.K., Akhmedinov, S.N. Quantitative development and distribution of zooplankton in medium lakes of the Kostanay Region (North Kazakhstan Region). International Journal of Environmental and Science Education, 2016, 11(15), c.

8193-8210, ijese.2016.620

41. Somzhurek, B.Z., Yessengaliyeva, A.M., Medeubayeva, Z.M., Makangali, B.K. Central Asia and regional security. Communist and Post-Communist Studies, 2018, 51(2), c. 161-171.

42. Sempau, J.; Badal, A.; Brualla, L. A PENELOPE-based system for the automated Monte Carlo simulation of clinacs and voxelized geometries-Application to far-from-axis fields. Med. Phys. 2011, 38, 5887-5895.

43. Gasull, M.; Royo, P.; Cuadrado, R. Design a RPAS Software Architecture over DDS. Master's Thesis, Castelldefels School of Telecommunications and Aerospace Engineering, Castelldefels, Spain, 2016.

44. Garro Fernandez, J.M. Drone Configuration for Seaside Rescue Missions. Master's Thesis, Universitat Politècnica de Catalunya, Barcelona, Spain, 2017.

45. Makangali, B., Amirbekova, S., Khamitova, M., Baydarov, E. Religious aspects of the Syrian crisis on social media. Central Asia and the Caucasus, 2020, 21(1), c. 102-111.
46. Macias, M. Study of 4G Propagation Conditions Using Unmanned Aerial Systems. Ph.D. Thesis, Universitat Politècnica de Catalunya, Barcelona, Spain, 2018.

47. Cloud Cap Technology. Piccolo II Product. 2017. Available online:

http://www.cloudcaptech.com/products/ detail/piccolo-ii (accessed on 7 July 2017).

48. Makangali, K. Konysbaeva, D.; Zhakupova, G.; Gorbulya, V.; Suyundikova, Zh. Study of sea buckthorn seed powder effect on the production of cooked-smoked meat products from camel meat and beef. Periodico Tche Quimica, 2019, 16: 130-139.

49. Lisitsyn A., Makangali K., Uzakov Y., Taeva A., Konysbaeva D., Gorbulya, V (2018) Study of the National Cooked Smoked Meat Products While Tests with Laboratory Animals at the Pathology Models with the Purpose to Confirm the set of Biocorrective Features. Current Research in Nutrition and Food Science journal 6(2): 536-551.

50. 38. Guava EventBus. Available online: https://github.com/google/guava/wiki/EventBusE xplained (accessed on 12 September 2018).

51. 39. Message Queuing Telemetry Transport (MQTT). Available online: http://mqtt.org/ (accessed on 12 September 2018).

52. 40. MAVLink Micro Air Vehicle Communication Protocol. Available online: http://qgroundcontrol.org/ mavlink/start (accessed on 12 September 2018).

53. 41. Hibernate. Available online: http://hibernate.org/ (accessed on 12 September 2018).

54. 42. H2 Database Engine. Available online: http://www.h2database.com/html/main.html (accessed on 12 September 2018).

55. 43. European Accreditation. EA-4/02 M: 2013 Evaluation of the Uncertainty of Measurement in Calibration. 2013. p. 75.

56. Dulambaeva, R., Orazalin, R., Tulembayeva, A., Peruashev, A. Assessing the development effect of governance. Life Science Journal, 2014, 11(SPEC. ISSUE 4), c. 144-152

57. Tulembayeva, A., Togusov, A., Berdibekov, A., Zhakashev, A. Assessment of the economic potential of the region in the context of national security. Journal of Advanced Research in Dynamical and Control Systems, 2020, 12(7 Special Issue), c. 1346-1352

58. Alexey Semchenko, Aigul Tulembayeva. Cataloging of supplies for the armed forces as a mechanism for improving their technical support in the interest of increasing the level of military security. Journal of Advanced Research in Dynamical and Control Systems, 2020, 12(7 Special Issue), c. 1353-1367. 